\title{
DAS KIRCHENPATRONATRECHT
}

IN DER

EVANGELISCH-LUTHERISCHEN LANDESKIRCHE

DES KÖNIGREICHS SACHSEN

VON

DR. IUR. OTTO ALBERT

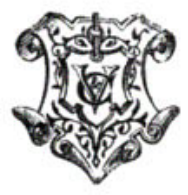

LEIPZIG

VERLAG VON VEIT \& COMP.

1908 
Leipziger juristische Inauguraldissertation 


\section{MEINEN ELTERN}


